\title{
A Novel Method for Fracture Toughness Evaluation of Tool Steels with Post-Tempering Cryogenic Treatment
}

\author{
Ramona Sola ${ }^{1, *}$, Roberto Giovanardi ${ }^{1}$, Giovanni Parigi ${ }^{2}$ and Paolo Veronesi ${ }^{1}$ \\ 1 Department of Engineering “E. Ferrari”, University of Modena and Reggio Emilia, Modena 41125, Italy; \\ roberto.giovanardi@unimore.it (R.G.); paolo.veronesi@unimore.it (P.V.) \\ 2 Stav, Barberino del Mugello, Florence 50031, Italy; parigi@stav.biz \\ * Correspondence: ramona.sola@unimore.it; Tel.: +039-059-2056224
}

Academic Editor: Filippo Berto

Received: 11 January 2017; Accepted: 20 February 2017; Published: 27 February 2017

\begin{abstract}
Cryogenic treatments are usually carried out immediately after quenching, but their use can be extended to post tempering in order to improve their fracture toughness. This research paper focuses on the influence of post-tempering cryogenic treatment on the microstructure and mechanical properties of tempered AISI M2, AISI D2, and X105CrCoMo18 steels. The aforementioned steels have been analysed after tempering and tempering + cryogenic treatment with scanning electron microscopy, $X$-ray diffraction for residual stress measurements, and micro- and nano-indentation to determine Young's modulus and plasticity factor measurement. Besides the improvement of toughness, a further aim of the present work is the investigation of the pertinence of a novel technique for characterizing the fracture toughness via scratch experiments on cryogenically-treated steels. Results show that the application of post-tempering cryogenic treatment on AISI M2, AISI D2, and $\mathrm{X} 105 \mathrm{CrCoMo} 18$ steels induce precipitation of fine and homogeneously dispersed sub-micrometric carbides which do not alter hardness and Young's modulus values, but reduce residual stresses and increase fracture toughness. Finally, scratch test proved to be an alternative simple technique to determine the fracture toughness of cryogenically treated steels.
\end{abstract}

Keywords: fracture toughness; scratch test; residual stress; tool steel; cryogenic treatment

\section{Introduction}

Cryogenic treatment is widely used to enhance the mechanical and physical properties of tool steels, hot work steels, and high carbon steels. According to literature [1-4], the greatest improvement in properties is obtained by carrying out the deep cryogenic treatment between quenching and tempering. However, in the case of tool steels, an improvement can be obtained even by performing cryogenic treatment at the end of the usual heat treatment cycle (i.e., treating the finished tools). This last solution is more flexible than the previous one, and can extend the use of the treatment to many practical applications [5,6].

Patil et al. [7] demonstrated that the application of cryogenic treatment to cutting tools improves wear resistance, hardness, dimensional stability, cutting tool durability, and tool life, and it reduces tool consumption, leading to a general reduction in production cost. Perez et al. [8] reported the importance of cryogenic treatments to increase toughness, thermal fatigue resistance, and wear resistance of hot work steel (AISI H13 as example) in order to maximize their lifetime. These benefits are achieved by deep cryogenic treatment because it decreases retained austenite content and it promotes the precipitation of fine carbides uniformly dispersed in martensite matrix, as reported by Sola et al. [9] and Gavriliuk et al. [10]. Retained austenite is a soft and unstable phase that reduces steel hardness and can be converted into martensite in working conditions and under stress, forming brittle (not tempered) martensite, with an increase of volume of $4 \%$, inducing local stresses. Cryogenic treatment-by 
transforming retained austenite to martensite-improves dimensional stability. In addition to the transformation of retained austenite to martensite, secondary and fine carbides are formed in the structure, increasing mechanical properties, toughness, and wear resistance. According to Perez [8], quenching and cryogenic treatment generate a high internal stress state due to thermal stresses and the transformation of martensite into austenite. Furthermore, thermal stresses increase the number of structural defects and the carbon-supersaturated martensite becomes unstable. Carbon atoms move towards the new structural defects created, martensite is decomposed, and carbide precipitation takes place during the warming up phase to room temperature, producing a reduction of residual stress and resulting in a homogeneously dispersed network of tiny carbides.

The evolution of carbides precipitation in chromium-containing steels, molybdenum-containing steels, and chromium-molybdenum-containing steels was discussed by Perez et al. [8,11], Gavriliuk et al. [10], and Villa et al. [12,13], studying the low-temperature martensitic transformation in tool steels and high-carbon steels. With internal friction analysis, Mossbauer spectroscopy, and synchrotron X-ray diffraction, these authors demonstrated that the carbon atoms are immobile at temperatures below $-100{ }^{\circ} \mathrm{C}$, and the possibility of their diffusion exponentially decreases with decreasing temperature. Instead, during the heating up to room temperature from cryogenic temperature, an ageing of carbon-supersaturated martensite (starting from $-50^{\circ} \mathrm{C}$ ) leads to martensite decomposition (for example, in a spinodal-like decomposition of a supersaturated solution) into carbon-rich areas which could induce precipitation of nanometric carbides.

Cryogenic treatment barely changes the tensile mechanical properties and hardness of tool steel and hot work steel $[8,9,13-15]$. However, it is worth noting that cryogenic treatment notably improved the fracture toughness of such steels because a fine, homogeneously dispersed carbide precipitation and a tougher martensite matrix are formed (with lower carbon content).

In this framework, toughness measurement is an important tool to assess the effectiveness of the cryogenic treatment on such steels, but standard methods require careful sample preparation and dedicated equipment, while a simpler technique could be easily adopted as a quality control tool, as an alternative to ASTM E399 e BS 5447 standard method [16]. The most popular alternative method is the Vickers indentation fracture test, where the fracture toughness, $K c$, is determined throughout a Vickers probe and according to Equation (1):

$$
K c=\alpha\left[\frac{E}{H}\right]^{\frac{1}{2}}\left[\frac{P}{c_{0}{ }^{1 / 2}}\right]
$$

where $P$ is the indentation load, $E$ is the Young's modulus, $H$ is the hardness, $c_{0}$ is the average length of radial cracks generated during the indentation, and $\alpha$ is a dimensionless constant. Several authors proposed refinements to Equation (1) [17-19] derived from a combination of empirical tests and dimensional analysis. All these expressions account for the residual stress, the plastic dissipation inside the material, and the nature of cracks. Moreover, during indentation fracture testing, it is fundamental to take considerable care to measure the average length of the cracks that begin from the four corners of the probe. Despite advances in microscopic analysis, considerable uncertainties could occur because of the possibility of spalling around indentation impression and/or the skill or subjectivity of the observer. Akono et al. in [20] proposed an alternative novel technique to measure the fracture toughness by scratch testing. The authors derived the fracture toughness expression from linear elastic fracture mechanics, and in [21] applied these techniques to ceramics, metals, polymers, and in [22], to micro-particulate composites. Akono et al. in [21] proposed a detailed description of an analytical model (with theoretical hypothesis and pertinence), materials surface preparation (the same for nano-indentation or micro-indentation), and the equipment and testing procedure, and showed that the $K c$ values measured via scratch test were in agreement with literature values, with a relative error of $2 \%-8 \%$ for ceramics and $3 \%-7 \%$ for metals.

In general terms, the scratch test consists of pulling a probe across the surface of the material under a controllable applied normal stress, and it is relevant nowadays to several fields of science and 
engineering [23], ranging from strength characterization of ceramics [24] to adhesion of thin films and coatings [25-27] and wear and damage resistance of metals, especially adhesion resistance of nitrided and nitrocarburized steels [28,29] and polymers [30]. Akono et al. [23] demonstrated that the failure mode (fracture or plastic yielding) is influenced by the materials properties as well as geometry of the scratching tool. According to the authors, it is possible to link the forces acting on scratch tip and the tool geometry to the plane strain fracture toughness $K c$, according to the following equation:

$$
K c=\frac{F_{t}}{\sqrt{2 w d(w+2 d)}}
$$

where $F_{t}$ is the horizontal (tangential) force necessary for the movement of the indenter, $w$ is the blade (indenter tip) width, and $d$ is the measured penetration depth.

Hence, the aim of the current study is to investigate the effect of post-tempering cryogenic treatment on the microstructure and mechanical properties of three different steels-the tool steel AISI M2, the hot work steel AISI D2, and the high chromium knife steel X105CrCoMo18 steel—as well as to investigate the application of a novel technique for characterizing the fracture toughness via scratch test experiments, simpler than standard method.

\section{Materials and Methods}

Standard bars of AISI D2, AISI M2, and X105CrCoMo18 tool steels were cut to obtain samples of the required size ( $40 \mathrm{~mm}$ diameter). Chemical compositions are given in Table 1 . The samples were treated as summarized in Table 2. The cryogenic treatment investigated was carried out in liquid nitrogen (LN2) after tempering, using the following critical parameters: cryogenic temperature $-193{ }^{\circ} \mathrm{C}$, cooling rate $40{ }^{\circ} \mathrm{C} / \mathrm{h}$, soaking time $24 \mathrm{~h}$, heating rate to room temperature $40^{\circ} \mathrm{C} / \mathrm{h}$.

Fracture toughness tests were carried out on a CSM Instrument Revetest Micro scratch tester (Neuchatel, Switzerland). Before the test, the surface samples were prepared per the procedure described by Akono et al. in [21]. The specimens were tested with a $200 \mu \mathrm{m}$ Rockwell C diamond indenter at a scratching speed of $6 \mathrm{~mm} / \mathrm{min}$ with vertical force equal to $30 \mathrm{~N}$, and the scratch length was $6 \mathrm{~mm}$. The scratch tester measures the penetration depth. Compared to a standard fracture toughness test (ASTM E399: standard Test Method for Linear-Elastic Plane-Strain Fracture Toughness $K_{I c}$ of Metallic Materials), the scratch test is a non-destructive test and it can be replicated on different zones of the same sample, and it is easier to apply and more flexible because it is not necessary to manufacture a standard sample-only a proper preparation of the surface of the specimen is needed (polishing).

Table 1. Nominal chemical composition of steels used in the investigation (wt \%).

\begin{tabular}{cccccccccc}
\hline Material & C & Si & Mn & Cr & Mo & V & W & Co & Fe \\
\hline AISI D2 & 1.50 & 0.30 & 0.30 & 11.50 & 0.70 & 1.00 & - & - & bal. \\
AISI M2 & 0.9 & 0.3 & 0.25 & 4.10 & 5.00 & 1.80 & 6.40 & - & bal. \\
X105CrCoMo18 & 1.09 & 0.40 & 0.40 & 17.30 & 1.10 & 0.10 & - & 1.50 & bal. \\
\hline
\end{tabular}

The microstructure of the treated samples was studied using a NOVA NanoSEM450, FEI Company-Bruker corporation (Hillsboro, OR, USA), scanning electron microscope (SEM) and the residual stresses were measured using Z-ray $\sin ^{2} \psi$ method (ENIXE-TTX Residual Stress Diffractometer) with a Co tube radiation, $24.5 \mathrm{kV}$ as tension, and $5.5 \mathrm{~mA}$ as current, 7 acquisition in $\psi$ on 156 degree $2 \theta$ angle. To obtain samples suitable for the microstructural analysis, the specimens were properly polished and etched with Murakami's reagent $\left(10 \mathrm{~g} \mathrm{~K}{ }_{3} \mathrm{Fe}(\mathrm{CN})_{6}, 10 \mathrm{~g} \mathrm{KOH}, 100 \mathrm{~mL}\right.$ water). Vickers HV1 microhardness tests were performed with a Vickers 432-SVD, Wolpert Wilson Instruments, INSTRON Company (Norwood, MA, USA), microhardness tester applying $9.8 \mathrm{~N}$ as normal force and a dwell time equal to $10 \mathrm{~s}$. 
Table 2. List of treatment conditions considered.

\begin{tabular}{|c|c|c|}
\hline Material & Sample Code & Treatment \\
\hline \multirow[t]{2}{*}{ AISI D2 } & $\mathrm{D} 2-\mathrm{C}$ & $\begin{array}{l}\text { Vacuum quenching at } 1080^{\circ} \mathrm{C} \text {, vacuum tempering at } 4800^{\circ} \mathrm{C} \text {, cryogenic } \\
\text { treatment at }-80^{\circ} \mathrm{C} \text { for } 2 \mathrm{~h} \text { in liquid nitrogen (LN2), tempering at } 480^{\circ} \mathrm{C} \text {, } \\
\text { cryogenic treatment at }-193^{\circ} \mathrm{C} \text { in LN2 for } 24 \mathrm{~h}\end{array}$ \\
\hline & D2 & $\begin{array}{l}\text { Vacuum quenching at } 1080^{\circ} \mathrm{C} \text {, vacuum tempering at } 480^{\circ} \mathrm{C} \text {, cryogenic } \\
\text { treatment at }-80^{\circ} \mathrm{C} \text { for } 2 \mathrm{~h} \text { in LN2, tempering at } 480^{\circ} \mathrm{C}\end{array}$ \\
\hline \multirow{2}{*}{ AISI M2 } & M2-C & $\begin{array}{l}\text { Vacuum quenching at } 1080^{\circ} \mathrm{C} \text {, three vacuum tempering at } 550^{\circ} \mathrm{C} \text { for } 2 \mathrm{~h} \text {, } \\
\text { cryogenic treatment at }-193^{\circ} \mathrm{C} \text { in LN2 for } 24 \mathrm{~h}\end{array}$ \\
\hline & M2 & Vacuum quenching at $1080^{\circ} \mathrm{C}$, three vacuum tempering at $550^{\circ} \mathrm{C}$ for $2 \mathrm{~h}$ \\
\hline \multirow{2}{*}{ X105CrCoMo18 } & $\mathrm{X} 105-\mathrm{C}$ & $\begin{array}{l}\text { Vacuum quenching at } 1030^{\circ} \mathrm{C} \text {, vacuum tempering at } 500^{\circ} \mathrm{C} \text { for } 2 \mathrm{~h} \text {, } \\
\text { cryogenic treatment at }-193^{\circ} \mathrm{C} \text { in LN2 for } 24 \mathrm{~h}\end{array}$ \\
\hline & X105 & Vacuum quenching at $1030^{\circ} \mathrm{C}$, vacuum tempering at $500^{\circ} \mathrm{C}$ for $2 \mathrm{~h}$ \\
\hline
\end{tabular}

Nanoindentation tests were carried out in load control mode on a calibrated Ultra Nanoindenter (UNHT) by CSM Instrument (Neuchatel, Switzerland) equipped with a Berkovich diamond tip at a constant loading rate of $200 \mu \mathrm{N} \cdot \mathrm{s}^{-1}$, up to a maximum load of $30,000 \mathrm{mN}$, and the resolution of displacement $1 \mathrm{~nm}$. The $50 \mathrm{~s}$ total indentation time was divided into three segments, consisting of $20 \mathrm{~s}$ loading and unloading and $10 \mathrm{~s}$ holding time. The tests were performed by creating three $10 \times 10$ grids of indents spaced $100 \mu \mathrm{m}$ for a total of 300 indents for samples. More details of the nanoindentation test are discussed by Bocchini et al. in [31]. During the test, the nanoindenter records the penetration depth $h$ and the load $w$. The slope $\mathrm{d} w / \mathrm{d} h$ of the unloading curve at the beginning of unloading can be used to measure $E$ as described by Fougere et al. [32], Chen et al. [33], and Balijepalli et al. [34,35]. Chen et al. in [33] showed a typical nanoindentation test load-indentation depth curve, and the author explained how it is possible to calculate the plasticity factor $\eta_{p}$, defined as the ratio of plastic deformation work to total deformation work. A low value of $\eta_{p}$ means a high resistance to plastic deformation.

\section{Results and Discussion}

Figures 1-3 show the microstructure of non-cryogenically treated and post-tempering cryogenically treated samples.
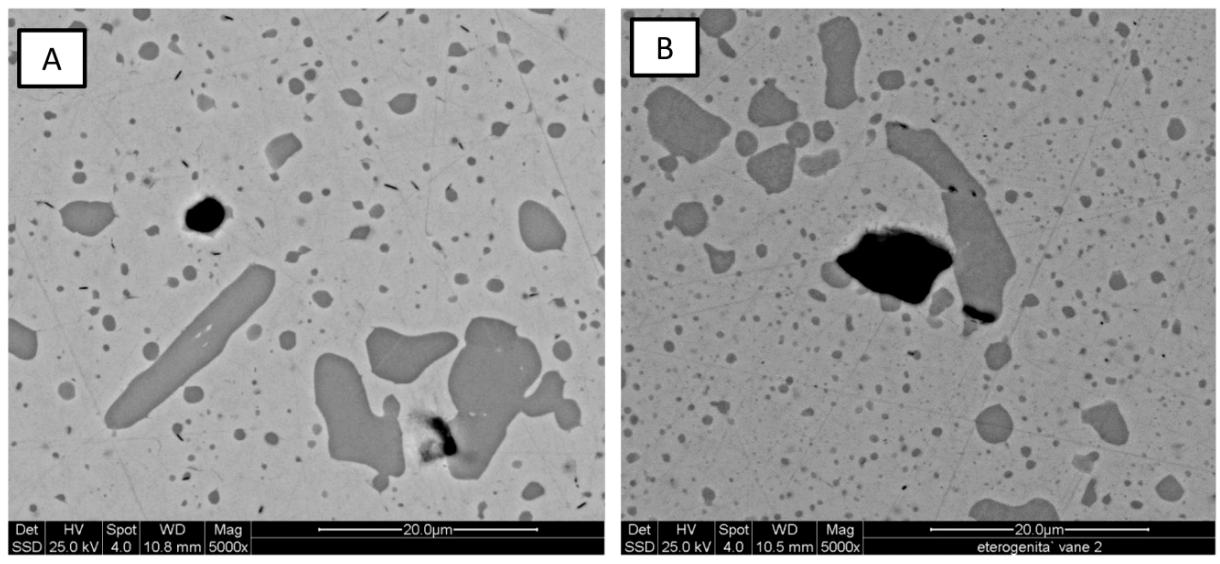

Figure 1. SEM micrographs of (A) D2 and (B) D2-C samples. 


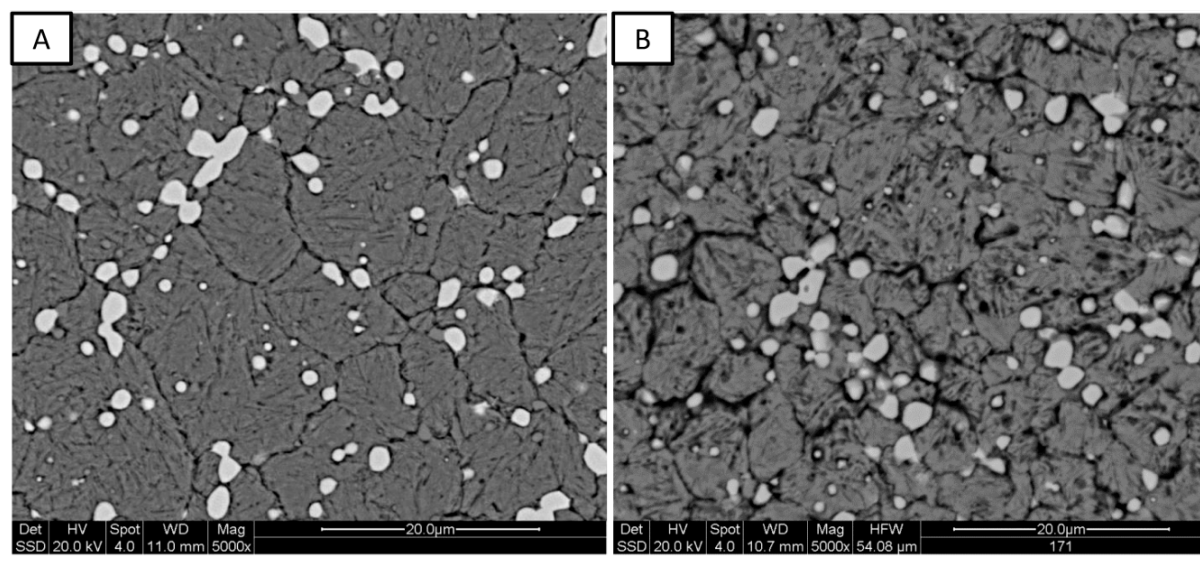

Figure 2. SEM micrographs of (A) M2 and (B) M2-C samples.
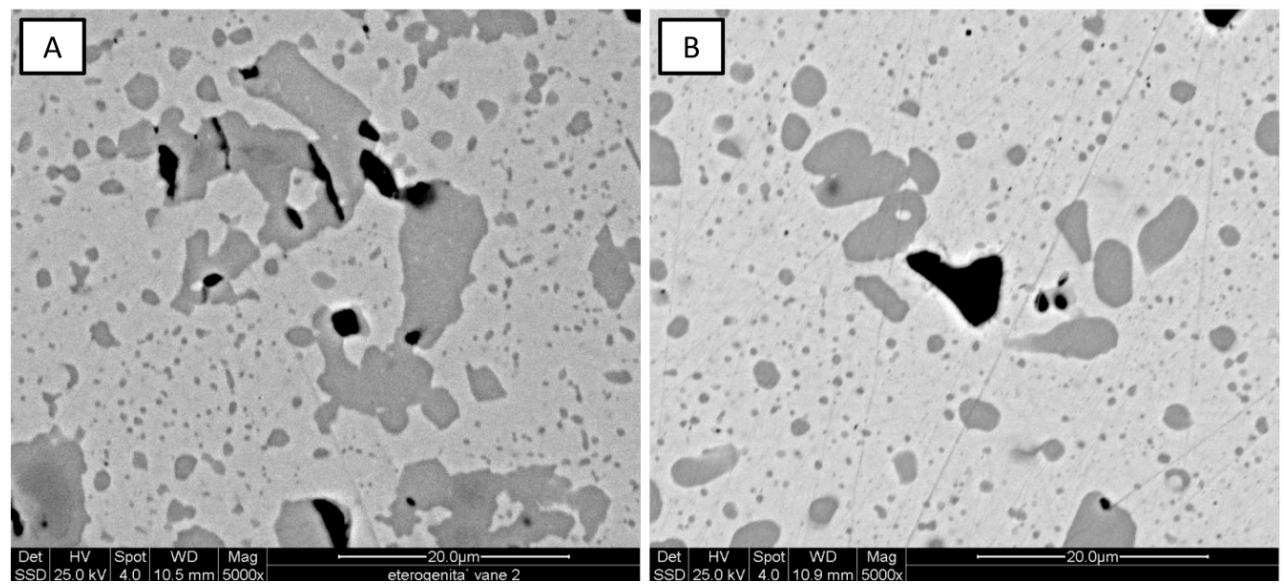

Figure 3. SEM micrographs of (A) X105 and (B) X105-C samples.

The AISI D2 samples (Figure 1) contain large primary carbides and smaller spherical carbides distributed homogeneously in a ferrite matrix parallel to the working direction. AISI M2 (Figure 2) cryogenically and non-cryogenically treated samples exhibit a martensitic matrix in which spheroidal carbides are distributed. X105CrCoMo18 samples (Figure 3) show a microstructure similar to AISI D2 samples. Image processing was performed using the public domain software ImageJ, and it was possible to estimate the average particle size and their volume fraction, as reported in Table 3.

Table 3. Particle size and volume fraction (\%) estimated using image analysis software.

\begin{tabular}{ccc}
\hline Sample & Particle Size $(\boldsymbol{\mu m})$ & Volume Fraction $(\%)$ \\
\hline D2-C & $0.444 \pm 0.1$ & $19.7 \pm 1$ \\
D2 & $0.555 \pm 0.1$ & $14.5 \pm 1$ \\
M2-C & $0.592 \pm 0.1$ & $9.1 \pm 1$ \\
M2 & $0.617 \pm 0.1$ & $7.0 \pm 1$ \\
X105-C & $0.394 \pm 0.1$ & $15.9 \pm 1$ \\
X105 & $0.472 \pm 0.1$ & $11.1 \pm 1$ \\
\hline
\end{tabular}

By analysing ten representative images for each sample, it was found that in all the cryogenically treated steels, the volume fraction of submicrometric carbides was higher compared to untreated samples. Moreover, the carbides were finer and more homogeneously distributed in the cryogenically treated samples. Some authors [4,11] attribute the effect to the activation of the tempering transformation of the martensite because of its oversaturation attained at $-196{ }^{\circ} \mathrm{C}$. Because of this, 
the carbide precipitation occurs during the subsequent heating to room temperature from cryogenic temperature, with higher activation energy, thus leading to higher nucleation rate and in turn to finer dimensions and a more homogeneous distribution.

A possible advantage resulting from the precipitation of fine carbides as result of cryogenic treatment is the improvement of the fracture toughness of the steel; an increase of Kc was obtained in the cryogenically treated samples, as shown in Table 4, where the fracture toughness values estimated via scratch test are reported. Optical micrographs of scratches are visible in Table 5, and a scratch at high magnification is reported in Figure 4. The Kc values reported in Table 4 agree with the fracture toughness values measured with the standard method, as reported by Molinari et al. in a paper [5] where the effect of deep cryogenic treatment carried out after tempering on the mechanical properties of AISI M2 and AISI H3 was studied. In all of the tool steels investigated, the cryogenic treatment increased the fracture toughness value because the reduction in microcracking tendency resulted from reduced internal stress when the fine carbide precipitation occurs [14]. This is visible in Tables 3 and 4, where the increment of carbides content and decrease of residual stresses are reported. The reduction in temperature reduced density lattice defects (dislocations) and thermodynamic instability of the martensite, which drives carbon and alloying elements to nearby defects. These clusters act as nuclei for the formation of fine carbides when stress is subsequently relieved. The precipitation of carbides that also occurs during heating from cryogenic treatment temperature is responsible for the residual stress relaxation [36]. The present investigation in tool steel favours this hypothesis for two reasons: (1) the distribution of the carbides in the cryogenically treated samples was more homogeneous than in the non-cryogenically treated samples, and (2) the carbide volume fraction in the cryogenically treated samples was higher than in the non-cryogenically treated ones. The precipitation of more hard carbides in the cryogenically treated samples can reduce the carbon-and also supersaturation-in the matrix, improving its toughness. The combination of higher carbides content and the reduction of residual stresses enhanced the steel fracture toughness. A higher carbides content decreased the microcracking tendency. Moreover, it is well known [15] that a reduction in carbide size reduces the probability of carbide fracture, and can therefore increase the fracture toughness under specific contact conditions. The microscopic analysis confirms all of these observations. Indeed, in Figure 4, a SEM micrograph of the scratch of the AISI D2-C sample is reported. It is clearly visible that the large carbides inside the scratch are cracked, and other cracks are around the smaller carbides. Along the propagation front, cracks breaks or surrounds the carbides, and for this the crack propagation slows down, with benefits on fracture toughness.

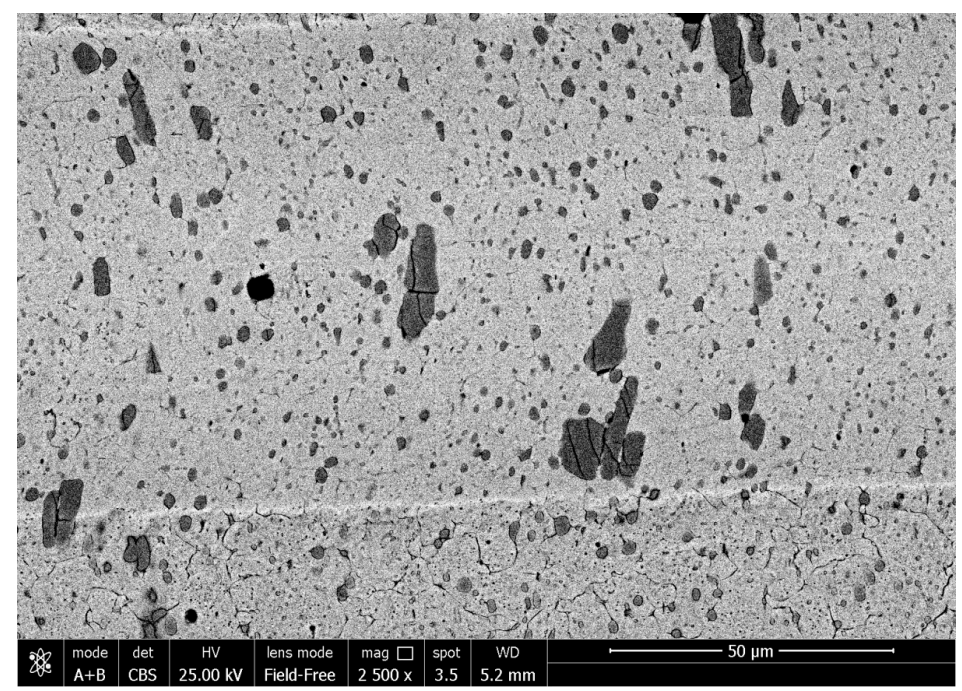

Figure 4. SEM micrograph of the scratch on the AISI D2-C sample. 
Microhardness (HV1) values are reported in Table 4. The results show that the cryogenic treatment-when carried out after the usual heat treatment-increased fracture toughness without affecting the hardness of the steel. Cryogenically treated samples were a little less hard than non-cryogenically treated ones, and the differences in hardness values were not significant; in other words, the increase in toughness was attained without reducing hardness, but this is ascribed to fine and homogeneously dispersed carbides that also decreased the residual stresses.

The obtained elastic modulus $(E)$ and plasticity factor $\left(\eta_{p} \%\right)$ are listed in Table 4 . The studied treatments did not essentially modify the Elastic Modulus value of all the steels investigated, but post-tempering cryogenic treatment incremented the plasticity factor $\left(\eta_{p} \%\right)$ value with respect to non-cryogenically treated materials, indicating that the martensite transformation and carbon precipitation enhanced the plastic deformation work and the toughness.

Table 4. Results of fracture toughness tests, residual stresses analysis, and Vickers hardness test.

\begin{tabular}{cccccc}
\hline Sample & $\boldsymbol{K c}\left(\mathbf{M P a} \cdot \mathbf{m}^{\mathbf{1 / 2}}\right)$ & Residual Stresses $\mathbf{( M P a )}$ & HV1 & E (GPa) & $\eta_{\boldsymbol{p}} \%$ \\
\hline D2-C & $47.06 \pm 1$ & $105 \pm 35$ & $807 \pm 6$ & $205 \pm 6$ & 57.7 \\
D2 & $36.24 \pm 1$ & $159 \pm 36$ & $814 \pm 23$ & $208 \pm 5$ & 50.1 \\
M2-C & $47.91 \pm 2$ & $-66 \pm 31$ & $899 \pm 22$ & $211 \pm 1$ & 61.3 \\
M2 & $36.74 \pm 2$ & $110 \pm 39$ & $902 \pm 16$ & $209 \pm 3$ & 49.4 \\
X105-C & $45.91 \pm 3$ & $281 \pm 28$ & $708 \pm 11$ & $212 \pm 2$ & 55.5 \\
X105 & $29.96 \pm 1$ & $324 \pm 36$ & $699 \pm 9$ & $211 \pm 4$ & 33.4 \\
\hline
\end{tabular}

Table 5. Optical micrographs of scratches. $100 \times$ magnifications.

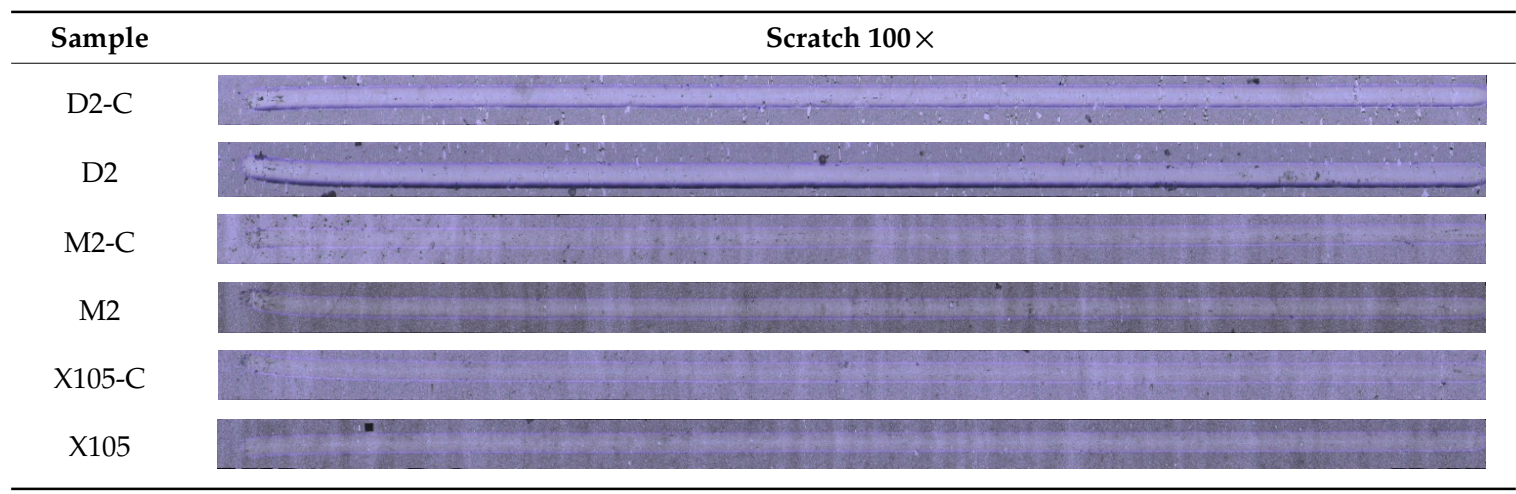

\section{Conclusions}

A novel method for fracture toughness measurements via scratch test was applied, and the estimated values were reasonably in agreement with the literature values measured with standard methods. This novel method for fracture toughness measurements is a non-destructive test that is easy to apply, flexible, and does not need a standard sample. Post-tempering cryogenic treatment barely changed the hardness of AISI M2, AISI D2, and X105CrCoMo18 steels, but it significantly influenced fracture toughness and residual stresses. The precipitation of finer carbides homogeneously dispersed in the martensite matrix due to cryogenic treatment did not alter the Young's Modulus, as measured by nanoindentation test in load control mode on, it decreased martensite residual stress, and improved plasticity factor and toughness.

Author Contributions: Ramona Sola and Giovanni Parigi designed and performed the experiments, Roberto Giovanardi and Paolo Veronese contributed the design of experiments and the results analysis.

Conflicts of Interest: The authors declare no conflict of interest. 


\section{References}

1. Podgornik, B.; Paulin, I.; Zajec, B.; Jacobson, S.; Leskovsek, V. Deep Cryogenic treatment of tool steels. J. Mater. Process. Technol. 2016, 229, 398-406. [CrossRef]

2. Baldissera, P.; Delprete, D. Deep Cryogenic treatment: A bibliografic review. Open Mech. Eng. J. 2008, 2, 1-11. [CrossRef]

3. Leskovsek, V.; Podgornik, B. Vacuum heat treatment, deep cryogenic treatment and simultaneous pulse plasma nitriding and tempering of P/M S390MC steel. J. Mater. Sci. Eng. A 2012, 531, 119-129. [CrossRef]

4. Das, D.; Sarkar, R.; Dutta, A.K.; Ray, K.K. Influence of sub-zero treatments on fracture toughness of AISI D2 steel. Mater. Sci. Eng. A 2010, 528, 589-603. [CrossRef]

5. Molinari, A.; Pellizzari, M.; Gialanella, S.; Straffelini, G.; Stiasny, K.H. Effect of deep cryogenic treatment on the properties of tool steel. J. Mater. Process. Technol. 2001, 118, 350-355. [CrossRef]

6. Pellizzari, M.; Molinari, A.; Giardini, L.; Maldarelli, L. Deep Cryogenic treatment of AISI M2 high speed steel. Int. J. Microstruct. Mater. 2008, 3, 383-390. [CrossRef]

7. Patil, N.; Kakkeri, S.; Sangamesh. Effect of cryogenic treated and untreated tool on its tool life-Review. Int. J. Sci. Res. 2012, 3, 141-145.

8. Perez, M.; Belzunce, F.J. The effect of deep cryogenic treatments on the mechanical proprieties of an AISI H13 steel. Mater. Sci. Eng. A 2015, 624, 32-40. [CrossRef]

9. Sola, R.; Poli, G.; Giovanardi, R.; Veronesi, P.; Parigi, G. Effect of deep cryogenic treatment on the properties of AISI M2 steel. In Proceedings of the European Conference on Heat Treatment 2015 and 22nd Heat Treatment and Surface Engineering from Tradition to Innovation Congress, Venice, Italy, 20-22 May 2015.

10. Gavrilijuk, V.; Theisen, W.; Sirosh, V.V.; Polshin, E.V.; Kortmann, A.; Mogilny, G.S.; Petrov, Y.N.; Tarusin, Y.V. Low-temperature martensitic transformation in tool steels in relation to their deep cryogenic treatment. Acta Mater. 2013, 61, 1705-1715. [CrossRef]

11. Perez, M.; Rodriguez, C.; Belzunce, F.J. The use of cryogenic treatment to increase fracture toughness of a hot work tool steel used to make forging dies. Procedia Mater. Sci. 2014, 3, 604-609. [CrossRef]

12. Villa, M.; Pantleon, K.; Somers, M.A.J. Evolution of compressive strains in retained austenite during sub-zero Celsius martensite formation and tempering. Acta Mater. 2014, 65, 383-392. [CrossRef]

13. Villa, M.; Grumsen, F.B.; Pantleon, K.; Somers, M.J. Martensitic transformation and stress partitioning in a high-carbon steel. Scr. Mater. 2012, 67, 621-624. [CrossRef]

14. Huang, J.Y.; Zhu, Y.T.; Liao, X.Z.; Beyerlein, I.J.; Bourke, M.A.; Mitchell, T.E. Microstructure of cryogenic treated M2 tool steel. Mater. Sci. Eng. A 2003, 339, 241-244. [CrossRef]

15. Singh, M.; Singh, H. Influence of deep-cryogenic treatment on the wear behavior and mechanical properties of mild steel. Int. J. Res. Eng. Technol. 2014, 4, 169-173.

16. ASTM International. ASTM E399-12e3: Standard Test Method for Linear-Elastic Plane-Strain Fracture Toughness $K_{\text {Ic }}$ of Metallic Materials; ASTM International: West Conshohocken, PA, USA, 2012.

17. Quinn, G.D.; Bradt, R.C. On Vickers fracture Toughness Test. J. Am. Ceram. Soc. 2007, 90, 673-680. [CrossRef]

18. Harding, D.S.; Oliver, W.C.; Pharr, G.M. Cracking during nanoindentation and its use in the measurement of fracture toughness. In Proceedings of the Fall meeting of the Materials Research Society (MRS), Boston, MA, USA, 28 November-9 December 1994; pp. 663-668.

19. Widjaja, S.; Yip, T.H.; Limarga, A.M. Measurement of creep-induced localized residual stress in soda-lime glass using nano-indentation technique. Mater. Sci. Eng. A 2001, 318, 211-215. [CrossRef]

20. Akono, A.T.; Ulm, F.J. Scratch test model for the determination of fracture toughness. Eng. Fract. Mech. 2011, 78, 334-342. [CrossRef]

21. Akono, A.T.; Randall, N.X.; Ulm, F.J. Experimental determination of the fracture toughness via microscratch tests: Application to polymers, ceramics, and metals. J. Mater. Res. 2012, 27, 485-493. [CrossRef]

22. Bouché, G.A.; Akono, A.T. Micromechanics-based estimates on the macroscopic fracture toughness of micro-particulate composites. Eng. Fract. Mech. 2015, 148, 243-257. [CrossRef]

23. Akono, A.T.; Alm, F.J. An improved technique for characterizing the fracture toughness via scratch test experiments. Wear 2014, 313, 117-124. [CrossRef]

24. ASTM International. ASTM Standard C1624: Standard Test Method for Adhesion Strenght and Mechanical Failure Modes of Ceramics Coatings by Quantitative Single Point Scratch Testing; ASTM International: West Conshohocken, PA, USA, 2015. 
25. Bull, S.J.; Berasetegui, E.G. An overview of the potential of quantitative coating adhesion measurement by scratch testing. Tribol. Int. 2006, 39, 91-114. [CrossRef]

26. Nohava, J.; Bonferroni, B.; Bolelli, G.; Lusvarghi, L. Interesting aspects of indentation and scratch methods for characterization of thermally-sprayed coatings. Surf. Coat. Technol. 2010, 205, 1127-1131. [CrossRef]

27. Taurino, R.; Barbieri, L.; Bondioli, F. Surface properties of new green building material after $\mathrm{TiO}_{2}-\mathrm{SiO}_{2}$ coatings deposition. Ceram. Int. 2016, 42, 4866-4874. [CrossRef]

28. Sola, R.; Poli, G.; Veronesi, P.; Giovanardi, R. Effects of surface morphology on the wear and corrosion resistance of post-treated Nitrided and nitrocarburized 42CrMo4 steel. Metall. Mater. Trans. A 2014, 45, 2827-2833. [CrossRef]

29. Sola, R. Post-treatment surface morphology effect on the wear and corrosion resistance of nitrided and nitrocarburized 41CrAlMo7 steel. Metall. Ital. 2010, 102, 21-31.

30. Taurino, R.; Fabbri, E.; Pospiech, D.; Synytska, A.; Messori, M. Preparation of scratch resistant superhydrophobic hybrid coatings by sol-gel process. Prog. Org. Coat. 2014, 77, 1635-1641. [CrossRef]

31. Bocchini, G.F.; Poli, G.; Sola, R.; Veronesi, P. Comparison-By nanoindentation-Among PM steels obtained from diffusion-bonded powders (nominally equivalent). In Proceedings of the World Powder Metallurgy Congress and Exhibition, Florence, Italy, 10-14 October 2010; Volume 3.

32. Fougere, G.E.; Riester, L.; Ferber, M.; Weetman, J.R.; Siegal, R.W. Young's modulus of nanocrystalline Fe measured by nanoindetation. Mater. Sci. Eng. A 1995, 204, 1-6. [CrossRef]

33. Chen, H.T.; Yan, M.F.; Fu, S.S. Martensite transformation induced by plasma nitrocarburizing on AISI304 austenitic stainless steel. Vacuum 2014, 105, 33-38. [CrossRef]

34. Balijepalli, S.K.; Colantoni, I.; Donnini, R.; Kaciulis, S.; Lucci, M.; Montanari, R.; Ucciardello, N.; Varone, A. Modulo elastico della fase $S$ in un acciaio 316 L kolsterizzato. Metall. Ital. 2013, 1, $42-47$.

35. Balijepalli, S.K.; Colantoni, I.; Donnini, R.; Kaciulis, S.; Montanari, R.; Varone, A. Young's modulus profile in kolsterized AISI 316 L steel. Mater. Sci. Forum 2013, 762, 183-188. [CrossRef]

36. Senthilkumar, D. Influence of shallow and deep cryogenic treatment on residual state of stress of 4140 steel. J. Mater. Process. Technol. 2011, 211, 396-401. [CrossRef]

(C) 2017 by the authors. Licensee MDPI, Basel, Switzerland. This article is an open access article distributed under the terms and conditions of the Creative Commons Attribution (CC BY) license (http:/ / creativecommons.org/licenses/by/4.0/). 